\title{
Preferences, Prices, and Ratings in Risky Decision Making
}

\author{
Barbara A. Mellers and Shi-jie Chang \\ University of California, Berkeley
}

\author{
Michael H. Birnbaum \\ California State University, Fullerton
}

\author{
Lisa D. Ordóñez \\ University of California, Berkeley
}

\begin{abstract}
Systematically different preference orders are obtained when different procedures are used to elicit preferences for gambles. Three new experiments found different preference orders with attractiveness ratings, risk ratings, buying prices, selling prices, avoidance prices, and strength-ofpreference judgments. Preference reversals persisted even when Ss were given financial incentives to motivate them to rank the gambles identically. Results were consistent with a change-ofprocess theory in which Ss are assumed to use different strategies in different tasks with the same scales. Attractiveness and risk ratings could be described by an additive combination of probability and amount, and prices could be predicted by a multiplicative combination of the same scales. Strength-of-preference judgments were consistent with a contrast-weighting model in which the weight of a dimension (either probability or amount) depends on the contrast between the 2 gambles along that dimension.
\end{abstract}

Since the time of Bernoulli (1738/1954), normative theories of decision making have asserted that people should select the course of action with the higher expected utility. Although several definitions of utility have been proposed, most normative theories begin with the premise that the decision maker can rank order the options with respect to preference. Recent research in psychology and economics has demonstrated that systematically different preference orders are obtained, depending on the procedure used to elicit preferences.

Lichtenstein and Slovic (1971) and Lindman (1971) provided early demonstrations of preference reversals in risky decision making. Lichtenstein and Slovic (1971) presented subjects with several pairs of gambles that were matched on expected value. For example, one of the gambles was a .97 chance to win $\$ 4$, otherwise lose $\$ 1$. This gamble is denoted $(\$ 4, .97 ;-\$ 1)$. The other was a .31 chance to win $\$ 16$, otherwise lose $\$ 1.50$, denoted by $(\$ 16, .31 ;-\$ 1.5)$. When asked which gamble they would prefer to play, subjects chose $(\$ 4, .97 ;-\$ 1)$ over $(\$ 16, .31 ;-\$ 1.5)$. When asked to state the minimum price they would accept to sell the gambles, subjects reported a higher selling price for $(\$ 16, .31 ;-\$ 1.5)$ than for $(\$ 4, .97 ;-\$ 1)$.

These findings led to a number of empirical investigations, some of which attempted to eliminate preference reversals but instead replicated and extended them (Goldstein \& Einhorn, 1987; Grether \& Plott, 1979; Hamm, 1979; Johnson, Payne, \& Bettman, 1988; Lichtenstein \& Slovic, 1973; Mowen \& Gentry, 1980; Pommerehne, Schneider, \& Zweifel, 1982;

This research was supported by National Science Foundation Grant SES-8908698 to Barbara A. Mellers.

We thank Jonathan Baron, Karen Biagini, Jerome Busemeyer, Alan Cooke, Duncan Luce, Nicholas Maxwell, Thomas Wallsten, Elke Weber, and Tom Wickens for very helpful comments.

Correspondence concerning this article should be addressed to Barbara A. Mellers, Department of Psychology, University of California, Berkeley, California 94270 . Electronic mail may be sent to Mellers @ violet.berkeley.edu.
Reilly, 1982; Schkade \& Johnson, 1989; Slovic \& Lichtenstein, 1983). Preference reversals have also generated considerable theoretical attention (Bostic, Herrnstein, \& Luce, 1990; Busemeyer \& Goldstein, in press; Goldstein \& Busemeyer, in press; Holt, 1986; Karni \& Safra, 1987; Loomes, 1990; Loomes \& Sugden, 1983; Tversky, Slovic, \& Kahneman, 1990).

\section{Change-of-Process Theory}

Some researchers have theorized that decision strategies depend on a variety of factors such as the context, the effort required, the accuracy needed, the information display, and the cost of the decision (Lichtenstein \& Slovic, 1971; Payne, 1973, 1976, 1982; Slovic \& MacPhillamy, 1974). The idea that the preference reversal phenomenon might be caused by different decision rules was considered by Lichtenstein and Slovic (1971), Johnson et al. (1988), and Schkade and Johnson (1989). Mellers, Ordóñez, and Birnbaum (in press) recently proposed a change-of-process theory for preference reversals between ratings and prices. In this account, preference reversals are attributed to variations in the decision strategies used to combine information. Change-of-process theory goes beyond previous accounts by proposing specific decision rules for prices and ratings and by assuming scale convergence.

Consider a gamble with specified probability, $p$, to win an amount, $x$, otherwise nothing $(x, p ; 0)$. The change-of-process theory asserts that under some conditions, ratings of the attractiveness of gambles can be described by an additive model:

$$
A(x, p ; 0)=J_{\mathrm{A}}[k s(p)+u(x)],
$$

where $A(x, p ; 0)$ is the attractiveness rating, $s(p)$ is the subjective weight that depends on the probability of winning, $u(x)$ is the utility of the amount to win, $J_{\mathrm{A}}$ is a monotonic judgment function, and $k$ is a scaling constant that calibrates subjective 
weights and utilities on the same scale. ${ }^{3}$ Buying prices, on the other hand, are described by a multiplicative model:

$$
\mathrm{P}_{\mathrm{B}}(x, p ; 0)=J_{\mathrm{B}}[s(p) \cdot u(x)],
$$

where $\mathrm{P}_{\mathrm{B}}(x, p ; 0)$ is the buying price, and $J_{\mathrm{B}}$ is a monotonic judgment function for buying prices.

The key premise in the change-of-process theory is that of scale convergence (Birnbaum, 1974; Birnbaum \& Veit, 1974). Although the models of ratings and prices change from additive to multiplicative in Equations 1 and 2, utilities and subjective probabilities are assumed to be independent of the task. The assumption that $u(x)$ and $s(p)$ are the same in Equations 1 and 2 leads to strong testable implications among psychological theories of preference reversals.

Two rival psychological accounts of preference reversals have been proposed: expression theory (Goldstein \& Einhorn, 1987) and contingent weighting theory (Tversky, Sattath, \& Slovic, 1988). Expression theory attributes preference reversals to changes in the mapping from a gamble's components to the response. This transformation is assumed to differ predictably for each gamble and for each response mode. Contingent weighting theory postulates that preference reversals are due to variations in the stimulus weighting. The weight of an attribute is assumed to depend on its compatibility with the response, so monetary outcomes are thought to be weighted more heavily in prices than in ratings.

Mellers et al. (in press) developed direct tests among the three theories. Evidence was inconsistent with expression theory and contingent weighting theory but could be described by change-of-process theory. Mellers et al. (in press) explored other implications of change-of-process theory. Evidence indicated that the stimulus context could also influence preference orders, which is consistent with a change-of-process account. The inclusion of certain stimuli appeared to "steer" subjects away from one decision strategy and toward another.

In this article, change-of-process theory will be extended to other response modes, including selling prices, risk ratings, unattractiveness ratings, avoidance prices, and strength-ofpreference judgments. Change-of-process theory refers to Equation I for ratings, Equation 2 for prices, and a new representation for strength-of-preference judgments that preserves scale convergence. Strength of preference introduces some new considerations that require further elaboration.

\section{Strength of Preference}

One way to investigate preference is to use binary choice. On each trial, subjects state their preference. A stochastic preference for gamble $i$ over gamble $j$ is said to occur when $P(i, j)$, the proportion of times $i$ is chosen over $j$, exceeds .5 . Strength of preference is sometimes defined as an increasing function of $P(i, j)$, as in Thurstone's (1927) law of comparative judgment, which assumes that choice proportions are an increasing function of the difference between the utilities of $i$ and $j$.

Most theoretical accounts of binary choice imply some form of stochastic transitivity (Coombs, 1983; Tversky, 1969). According to weak stochastic transitivity, if $P(i, j) \geq .5$ and $P(j, k) \geq .5$, then $P(i, k) \geq .5$. If the first two conditions hold, then moderate stochastic transitivity requires $P(i, k) \geq$ $\min (P(i, j), P(j, k))$, and strong stochastic transitivity or simple scalability states that $P(i, k) \geq \max (P(i, j), P(j, k)$ ) (Krantz, 1964; Tversky \& Russo, 1969). Strong stochastic transitivity is implied by Luce's (1959) choice rule, Thurstone's (1927) law (Case 5), and other models.

Empirical investigations indicate that weak and moderate stochastic transitivity are often satisfied, although a few exceptions have been noted (Tversky, 1969). Strong stochastic transitivity is frequently violated (Busemeyer, 1985; Coombs, 1958; Rumelhart \& Greeno, 1971; Tversky \& Russo, 1969).

Strength-of-preference judgments provide another basis for measuring preference (Birnbaum, 1974; Sarin, 1982). On any single trial, subjects are asked to state not only the direction of their preference but also the magnitude of that preference. Assume that a judgment of 0 represents indifference on a strength-of-preference scale, and $S(i, j)$ greater than (or less than) 0 represents a judged preference for $i$ over $j$ (or $j$ over $i)$. Weak transitivity states that if $S(i, j) \geq 0$ and $S(j, k) \geq 0$, then $S(i, k) \geq 0$. If the first two conditions hold, then moderate transitivity requires $S(i, k) \geq \min (S(i, j), S(j, k))$, and strong transitivity states that $S(i, k) \geq \max (S(i, j), S(j, k))$.

Strength-of-preference judgments and choice proportions could be related in several ways. For example, the sign of the preference judgment might be predictable from the choice proportion; that is, $S(i, j) \geq 0$ whenever $P(i, j) \geq .5$. Zakay (1984) reported that at least for some risky options, choice proportions and strength-of-preference judgments are monotonically related; that is, $S(i, j)=J P(i, j)]$, where $J$ is a monotonic function.

On the other hand, strength-of-preference judgments might be theoretically distinct from choice proportions and perhaps offer a solution to the violations of strong stochastic transitivity. To illustrate a violation of strong stochastic transitivity, consider the following choice problem. Subjects might be indifferent between expensive trips to Rome or Paris, so $P($ Rome, Paris $)=.5$. Adding $\$ 1$ to Rome causes all subjects to prefer Rome $+\$ 1$ to Rome, so $P($ Rome $+\$ 1$, Rome $)=1$. Subjects are still nearly indifferent between Paris and Rome $+\$ 1$, such that $P($ Rome $+\$ 1$, Paris $)=.51$. Strong stochastic transitivity implies that if $P($ Rome $+\$ 1$, Rome $)=1$, then $P$ (Rome + \$1, Paris) should also be 1 .

Violations of strong stochastic transitivity may occur in these situations because two processes influence choice: the true preference for one stimulus over another and the ease of discriminability between the stimuli being compared (Debreu, 1960; Restle, 1961; Tversky \& Russo, 1969). Tversky and Russo suggested that if stimuli are similar along one dimension, discrimination along another dimension might be enhanced, causing violations of strong stochastic transitivity.

Strength-of-preference judgments might reduce violations of strong transitivity by allowing subjects to express the magnitude of their preference for Rome $+\$ 1$ over Rome. In

\footnotetext{
${ }^{1}$ Although the scaling constant, $k$, might depend on the ranges of the independent variables used in different studies, it is assumed to be constant within a given experiment. For the special cases in which either $s(p)$ or $u(x)$ is zero, the response is assumed to be neutral or indifferent (see Mellers, Ordóñez, \& Birnbaum, in press).
} 


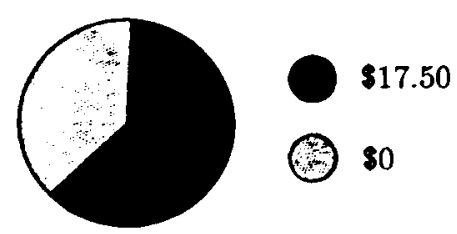

Figure 1. Format for display of gambles. (The black region corresponds to a probability of .63 to win $\$ 17.50$. The gray region depicts a .37 probability to receive zero.)

particular, if the preference for Rome $+\$ 1$ over Rome is minuscule, that is, $S$ (Rome $+\$ 1$, Rome $)=1$ on a scale from 0 to 100 , and $S$ (Rome, Paris) $=0$, subjects might also indicate a very slight preference for Rome $+\$ 1$ over Paris, that is, $S$ (Rome $+\$ 1$, Paris $)=1$, which is consistent with strong transitivity. Perhaps subjects would indicate that the addition of $\$ 1$ produces a tiny but easily detectable change in their preferences for both choices.

\section{Overview}

To extend the change-of-process theory to preference, it is necessary to postulate a model of the process. Then one can ask if the scales agree with those derived from models fit to ratings and prices. Consider two gambles, $i$ and $j$. Gamble $i$ has probability $p_{i}$ of winning $x_{i}$, otherwise nothing, and gamble $j$ has probability $p_{j}$ of winning $x_{j}$, otherwise nothing. One simple model for strength-of-preference judgments is a difference between products of utilities and subjective probabilities, as follows:

$$
S(i, j)=J_{\mathrm{S}}\left[u\left(x_{i}\right) \cdot s\left(p_{i}\right)-u\left(x_{j}\right) \cdot s\left(p_{j}\right)\right],
$$

where $S(i, j)$ is the judged strength of preference for gamble $i$ over gamble $j, u\left(x_{i}\right)$ and $u\left(x_{j}\right)$ are the utilities of the amounts to win, $s\left(p_{i}\right)$ and $s\left(p_{j}\right)$ are the subjective probabilities of winning, and $J_{\mathrm{S}}$ is a monotonic judgment function. Equation 3 implies all three forms of transitivity, in addition to other properties implied by a difference between two products.

If strength-of-preference judgments violate strong transitivity, then a generalization of Equation 3, referred to as the contrast-weighting model, might describe the results:

$$
S(i, j)=J_{\mathrm{S}}\left[u\left(x_{i}\right)^{\alpha_{i j}} \cdot s\left(p_{i}\right)^{\beta_{i j}}-u\left(x_{j}\right)^{\alpha_{i j}} \cdot s(p)^{\beta^{\beta_{i}}}\right],
$$

where $\alpha_{i j}$ and $\beta_{i j}$ depend on the degree of contrast in the utilities and subjective probabilities, respectively; that is, $\alpha_{i j}=$ $f\left(x_{i}, x_{j}\right)$, and $\beta_{i j}=g\left(p_{i}, p_{j}\right) . J_{\mathrm{S}}$ is a monotonic judgment function.

One simple representation of the weights, $\alpha_{i j}$ and $\beta_{i j}$, supposes that there are two weights for each dimension: one when values are similar along that dimension and another when values are dissimilar. Weights would presumably be smaller when differences along a dimension were small. When the difference along a dimension increased, weights would presumably be larger. The contrast-weighting model (Equation 4) could produce violations of all three types of transitivity, depending on the assumptions made about $f$ and $g$.

The present experiments evaluate the change-of-process theory with several different response modes. Of particular interest is whether the theory can be extended to strength-ofpreference judgments. In other words, is it possible to find a model for strength-of-preference judgments (such as Equations 3 or 4) with the same scales as those derived from the fit of Equations 1 and 2 to ratings and prices, respectively?

\section{Method}

Three experiments were performed with different subjects in each. In Experiment 1, subjects were shown binary gambles with a positive and a zero outcome in four different tasks: attractiveness ratings, buying prices, selling prices, and strength-of-preference judgments. Experiment 2 replicated Experiment 1 with financial incentives to investigate whether subjects, motivated to be consistent, would also show preference reversals. Experiment 3 examined preference reversals in the domain of losses. Subjects were presented with binary gambles having a negative or a zero outcome in four different tasks: unattractiveness ratings, risk ratings, avoidance prices, and strengthof-preference judgments.

\section{Experiment 1: Domain of Gains}

Stimuli. Gambles were displayed as in Figure 1 on an 11-in. $(27.9-\mathrm{cm})$ monitor. The circle was said to represent a spinner device, in which the outcome would depend on where the spinner pointed when it stopped. When the gambles were presented one at a time, pie charts were $2 \frac{1 / 4}{4}$ in. $(5.7 \mathrm{~cm})$ in diameter. When gambles were presented in pairs, they were each $15 / 8$ in. $(4.1 \mathrm{~cm})$ in diameter and were displayed simultaneously on the monitor.

Design. Gambles were constructed from a $6 \times 6$ (amount $\times$ probability) factorial design. Amounts to win were $\$ 3, \$ 5.40, \$ 9.70$, $\$ 17.50, \$ 31.50$, and $\$ 56.70$; probabilities of winning were $.05, .09$, $.17, .29, .52$, and .94 . Levels along both factors were chosen to be approximately geometrically spaced (within rounding) to create gambles varying in probability and amount with nearly equal expected values. Expected values for the gambles are shown in Table 1 .

Table 1

Expected Values for Gambles

\begin{tabular}{ccccccc}
\hline & \multicolumn{7}{c}{ Amount } \\
\cline { 2 - 7 } Probability & $\$ 3$ & $\$ 5.40$ & $\$ 9.70$ & $\$ 17.50$ & $\$ 31.50$ & $\$ 56.70$ \\
\hline .05 & 0.15 & 0.27 & 0.49 & 0.88 & 1.58 & 2.84 \\
.09 & 0.27 & 0.49 & 0.87 & 1.58 & 2.84 & 5.10 \\
.17 & 0.48 & 0.86 & 1.55 & 2.80 & 5.04 & 9.07 \\
.29 & 0.87 & 1.57 & 2.81 & 5.08 & 9.14 & 16.44 \\
.52 & 1.56 & 2.81 & 5.04 & 9.10 & 16.38 & 29.48 \\
.94 & 2.82 & 5.08 & 9.12 & 16.45 & 29.61 & 53.30 \\
\hline
\end{tabular}


In three tasks (attractiveness ratings, buying prices, and selling prices), subjects were presented with the 36 gambles, one at a time. A fourth task (strength of preference) investigated comparative judgments. Subjects were presented with gamble pairs constructed from a subset of the $36 \times 36$ (Gamble $1 \times$ Gamble 2 ) possible permutations in a factorial design. Of the 630 pair combinations, 225 pairs were nondominated (i.e., one gamble had a higher probability of winning and the other had a higher amount to win). These 225 pairs were used in the experiment and are shown as solid squares in Figure 2. Columns represent winning probabilities for Gamble 1, and rows show probabilities for Gamble 2. Amounts to win are not labeled in the figure, but they are indicated by spacing of squares within each level of probability. Because none of the gamble pairs were dominated, columns within each level of probability represent amount levels of $\$ 3$ to $\$ 31.50$, and rows within each level of probability represent amount levels of $\$ 5.40$ to $\$ 56.70$.

Instructions. In the attractiveness rating task, subjects rated gambles on a scale from 0 to $80(0=$ neither attractive nor unattractive, $40=$ attractive, and $80=$ very very attractive; integers between 0 and 80 were used to represent intermediate judgments). In the buying price task, subjects were asked to state the maximum amounts they would be willing to pay to play the gambles. For selling prices, subjects were told to assume that they owned the gambles. Their task was to state the minimum amounts they would be willing to accept to sell each gamble. In the strength-of-preference task, subjects were shown pairs of gambles, and they selected the gamble they would prefer to play. Then they rated the magnitude of their preference on a scale from 0 to $80(0=$ no preference, $40=$ prefer the gamble selected, and $80=$ very very much prefer the gamble selected).

Procedure. Subjects performed all four tasks at a computer terminal. Tasks were counterbalanced for order. Twelve of the 24 possible task orders were selected, and subjects were randomly assigned to one of the 12 orders. Orders were ABSP, ASBP, APBS,

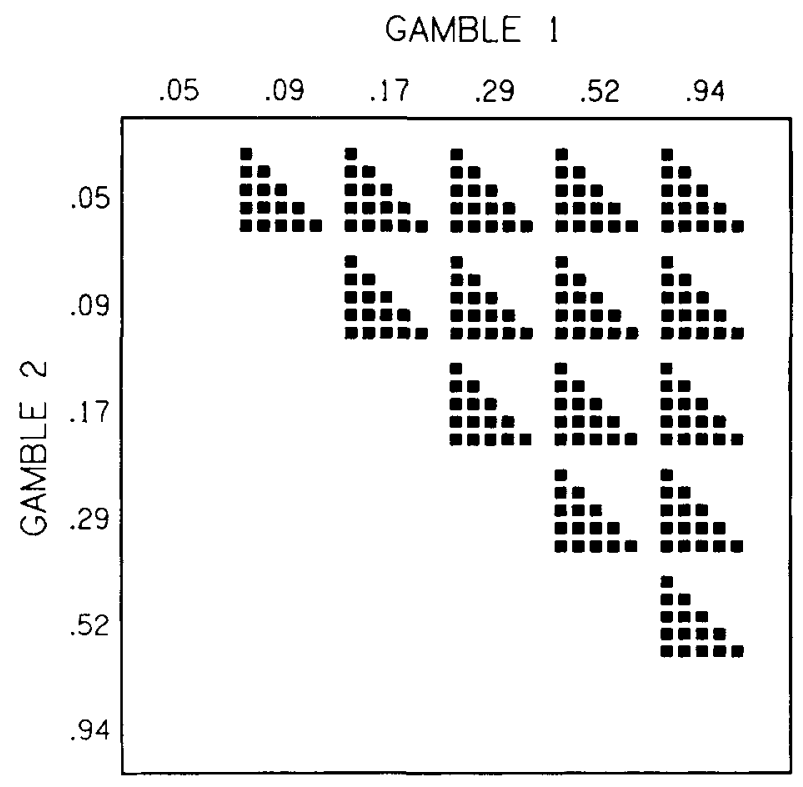

Figure 2. Experimental design for strength-of-preference judgments. (Columns and rows represent Gamble 1 and Gamble 2, respectively. Each probability has six levels of amount combined with it. A black square indicates that the gamble pair [Gamble 1 and Gamble 2] was presented for judgment in the design. Black squares show all pairs of gambles with distinct levels in which one gamble does not dominate the other.)
APSB, BSAP, SBAP, BSPA, SBPA, PABS, PASB, PBSA, and PSBA, where $A, B, S$, and $P$ denote attractiveness ratings, buying prices, selling prices, and strength of preference, respectively.

For each task, subjects read the instructions, practiced with a set of warm-up trials, completed the test trials, and wrote a paragraph describing what they did. There were five warm-up trials for each single-gamble task (attractiveness ratings, buying prices, and selling prices). Test trials were presented in a random order generated by the computer. For strength-of-preference judgments, there were 10 warmup trials, followed by 225 test trials. Trial order and gamble position (left vs. right) were randomized. Subjects worked at their own paces and were encouraged to take a short break after each task. The experiment took approximately $2 \mathrm{hr}$.

Participants. Subjects in all three experiments were undergraduates at the University of California, Berkeley. There were 48 subjects in Experiment 1 who received credit in a lower division psychology course for their participation. A few additional subjects who did not follow instructions were excluded from the analyses.

\section{Experiment 2: Financial Incentives}

This experiment was similar to Experiment 1, except that subjects were paid $\$ 10$ for their participation and were told that they would play four gambles at the end of the experiment, one gamble from each task. They were instructed that for the attractiveness rating task and the pricing tasks, two trials (gambles) would be randomly selected from the 36 possible trials. The gamble to which they had assigned a higher attractiveness rating (or the higher price) would be played with real consequences ( $1 / 4$ of the stated outcomes). For strength of preference, one trial (gamble pair) would be randomly selected from the 225 possible trials, and the gamble for which they had indicated a preference would be played. These financial incentives should have motivated subjects to rank the gambles identically in the four tasks, because the higher ranked gamble was played each time.

Subjects played the four gambles by rolling a 100 -sided die four times. Average winnings from the four gambles was $\$ 10.77$, and the average total payment to each subject was $\$ 20.77$.

Participants. There were 24 undergraduates who were recruited from the University of California, Berkeley, community.

\section{Experiment 3: Domain of Losses}

Stimuli and design. Gambles were similar to those in Experiment 1, except that positive outcomes were converted to negative outcomes (losses). All of the gambles now had negative expected values. In three tasks (unattractiveness ratings, risk ratings, and avoidance prices), subjects evaluated each gamble separately, and in the fourth task (strength of preference), subjects stated their preference for one gamble over another (the better of two evils).

Instructions. In the unattractiveness task, subjects rated the gamble on a scale from 0 to $80(0=$ neither attractive nor unattractive, $40=$ unattractive, and $80=$ very very unattractive $)$. In the risk task, subjects also used integers from 0 to $80(0=$ not at all risky, $40=$ risky, and $80=$ very very risky). For avoidance prices, subjects were told to assume that they owned the gamble and were asked to state the maximum amount they would be willing to pay to avoid playing it. This situation is analogous to buying insurance. Instructions for strength of preference were identical to those of Experiment 1.

Procedure. The procedure was similar to Experiment 1. Different groups of subjects received the four tasks in one of the following six task orders: ABPR, APBR, BAPR, BPAR, PABR, and PBAR, where $R, B, A$, and $P$ denote risk ratings, unattractiveness ratings, avoidance prices, and strength of preference, respectively. In all three experi- 


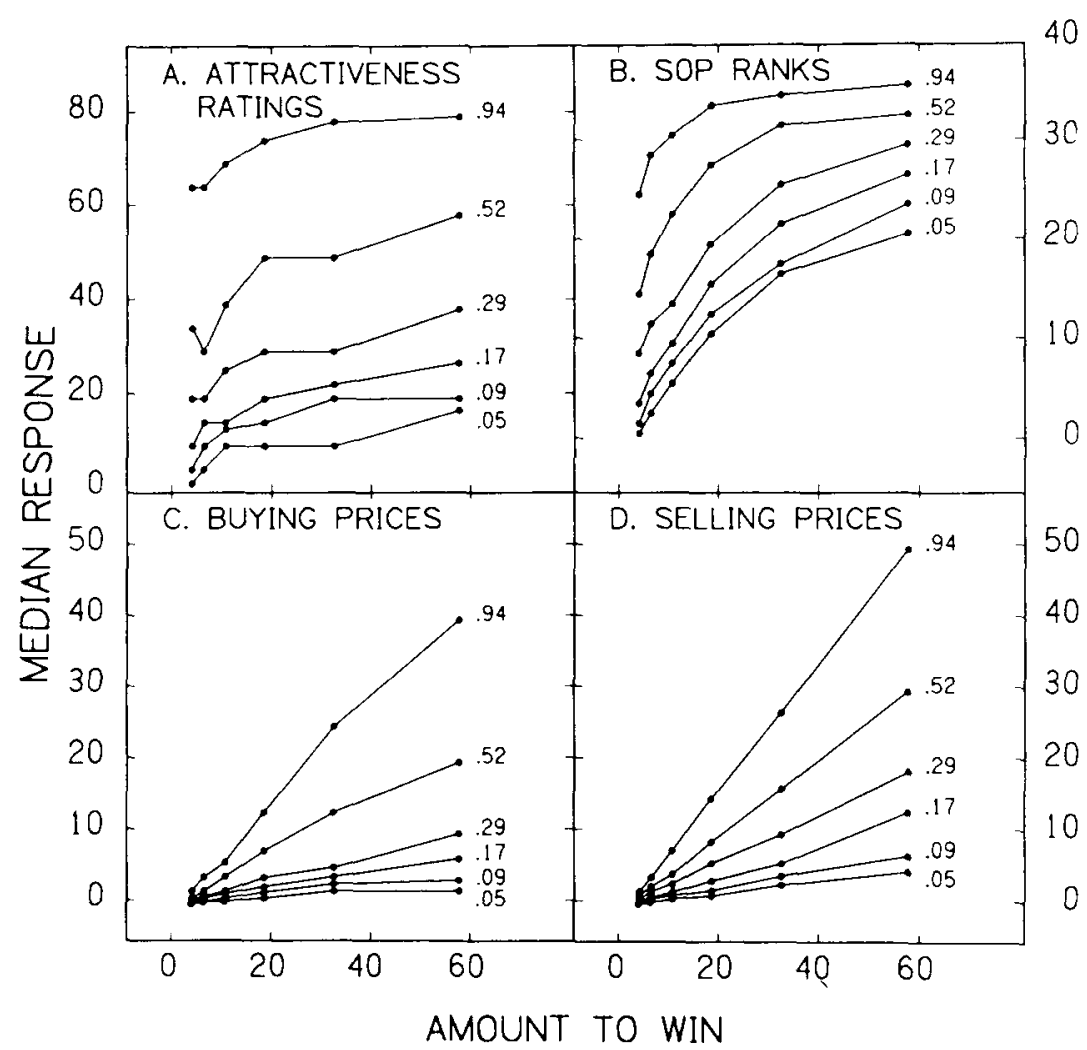

Figure 3. Median responses and ranks from Experiment 1. (Judged values of the gambles are plotted as a function of the amount to win, with a separate curve for each probability of winning. Panel $A$ shows median attractiveness ratings. Panel B presents the rank order of gambles inferred from strengthof-preference judgments; Numbers 1 and 36 refer to the lowest ranked and highest ranked gambles, respectively. Panels $C$ and $D$ show median buying prices and selling prices, respectively.)

ments, none of the main effects or interactions involving task order was significant, so subsequent analyses are collapsed over task orders.

Participants. There were 40 subjects in Experiment 3 who received credit in a lower division psychology course for their participation. A few additional subjects who did not follow instructions were excluded from the analyses.

\section{Results}

\section{Experiment 1: Domain of Gains}

Figure 3 displays median responses for the three singlegamble judgment tasks and ranks derived from median strength-of-preference judgments. Ranks were estimated from the strength-of-preference data to minimize violations of weak transitivity. Within each panel, the value or rank of a gamble is plotted as a function of the amount to win, with a separate curve for each probability of winning.

Panel A of Figure 3 shows the attractiveness ratings. Curves are nearly parallel as a function of amount to win and probability of winning. Parallelism is consistent with the theory that ratings are linearly related to an additive combination of probability and amount.

In theory, parallelism might result from an averaging of individual strategies in which subjects attend to only one dimension, either probability or amount. Individual subject data were plotted in the same way as in Panel A, and the overwhelming majority of subjects showed effects of both factors. As in the experiment of Mellers et al. (in press), attractiveness ratings appear to be consistent with an additive model at the individual subject level as well. In that experiment, the slopes of the curves were slightly steeper than in the present study; the effect of amount was greater. Perhaps this slight difference is due to the size of the probability display in the two experiments.

Panel B of Figure 3 presents the preference order derived from strength-of-preference judgments. Ordinate values refer to the rank order of gambles; numbers range from 1 (least preferred) to 36 (most preferred). Panels C and D of Figure 3

\footnotetext{
${ }^{2}$ This order was obtained as follows: First, median strength-ofpreference judgments were rescaled to two-way additivity of gamble $i \times$ gamble $j$, using Kruskal and Carmone's (1969) MONANOVA to fit the model $S(i, j)=J\left(\psi_{i}-\psi_{j}\right)$, where $S(i, j)$ is the strength-ofpreference judgment for gamble $i$ over gamble $j, J$ is a monotonic judgment function, and $\psi_{i}$ and $\psi_{j}$ represent the subjective worth of gambles $i$ and $j$, respectively. This model implies weak, moderate, and strong transitivity. Second, the rank order of the 36 values of $\psi$ was successively adjusted by switching pairs of gambles to minimize violations of weak transitivity.
} 
show buying and selling prices, respectively. Both sets of curves form bilinear fans, which are consistent with multiplicative models. Rank orders of gambles in these two tasks are similar, although selling prices are higher, exceeding buying prices by an average of $\$ 2.35$. Results in Panel $\mathrm{C}$ also resemble those found by Mellers et al. (in press).

The pattern of responses in Figure 3 for gambles with equal expected values is consistent with previous research on preference reversals. For example, the median attractiveness rating for the gamble with a .94 chance to win $\$ 3$ was higher than the rating of a .05 chance to win $\$ 56.70$, and the selling price for the .94 chance to win $\$ 3$ was lower than the selling price of a .05 chance to win $\$ 56.70$.

Reversals of preference were counted for all 55 pairs of gambles that were matched on expected value. The term $P$ Bet refers to the gamble in each pair with the higher probability of winning, and $\$ B e t$ refers to the gamble with the higher amount to win. The percentage of gamble pairs for which the P Bet was preferred to the $\$$ Bet varied across the four tasks. Those percentages were $2 \%, 25 \%, 60 \%$, and $89 \%$ in selling prices, buying prices, strength of preference, and attractiveness ratings, respectively.

Table 2 presents percentages of preference reversals in the medians for all six pairs of tasks. Entries are percentages of gamble pairs for which the $P$ Bet was ranked higher than the $\$$ Bet in the column task, and the $\$$ Bet was ranked higher than the $P$ Bet in the row task. Tasks were ordered from smallest to largest percentage of $P$ Bet preferences (i.e., selling prices, buying prices, strength of preference, and attractiveness ratings). This ordering results in a table in which preference reversals are frequent above the diagonal and infrequent below the diagonal. The highest percentage occurred between attractiveness ratings and selling prices. The $\mathrm{P}$ Bet had a higher attractiveness rating, and the $\$$ Bet received a higher selling price $95 \%$ of the time. Reversals between prices and strength-of-preference judgments were similar to those found by others with prices and choices; the $\mathrm{P}$ Bet was preferred to $\$$ Bet, and the $\$$ Bet received a higher selling price $60 \%$ of the time. Preference reversals below the diagonal ranged from $0 \%$ to $4 \%$. For all six pairs of tasks, the percentage of preference reversals above the diagonal was significantly greater than the corresponding percentage of preference reversals below the diagonal. ${ }^{3}$

Preference reversals were not limited to gamble pairs with equal expected values. Differences in expected values for nondominated gamble pairs that were not matched on expected value ranged from $\$ 0.21$ to $\$ 29.66$. Above the diago-

Table 2

Experiment 1: Percentage of Preference Reversals for Equal Expected Value Pairs in the Domain of Gains

\section{$P$ Bet ranked higher than $\$$ Bet}

\begin{tabular}{lccccc}
\cline { 2 - 5 } $\begin{array}{c}\text { \$ Bet ranked higher } \\
\text { than P Bet }\end{array}$ & $\begin{array}{c}\text { Selling } \\
\text { prices }\end{array}$ & $\begin{array}{c}\text { Buying } \\
\text { prices }\end{array}$ & $\begin{array}{c}\text { Strength of } \\
\text { preference }\end{array}$ & $\begin{array}{c}\text { Attractiveness } \\
\text { ratings }\end{array}$ \\
\hline Selling prices & - & $25 \%$ & $60 \%$ & $95 \%$ \\
Buying prices & $0 \%$ & - & $25 \%$ & $44 \%$ \\
Strength of preference & $2 \%$ & $4 \%$ & - & $20 \%$ \\
Attractiveness ratings & $0 \%$ & $0 \%$ & $0 \%$ & - \\
\hline
\end{tabular}

Note. Counts are based on median responses.
Table 3

Experiment 1: Median Percentage of Preference Reversals for Individual Subjects in the Domain of Gains

\begin{tabular}{lcccc}
\hline & \multicolumn{4}{c}{ P Bet ranked higher than \$ Bet } \\
\cline { 2 - 5 } $\begin{array}{c}\text { \$ Bet ranked higher } \\
\text { than P Bet }\end{array}$ & $\begin{array}{c}\text { Selling } \\
\text { prices }\end{array}$ & $\begin{array}{c}\text { Buying } \\
\text { prices }\end{array}$ & $\begin{array}{c}\text { Strength of } \\
\text { preference }\end{array}$ & $\begin{array}{c}\text { Atractiveness } \\
\text { ratings }\end{array}$ \\
\hline Selling prices & - & $22 \%$ & $36 \%$ & $51 \%$ \\
Buying prices & $5 \%$ & - & $24 \%$ & $35 \%$ \\
Strength of preference & $4 \%$ & $9 \%$ & - & $18 \%$ \\
Attractiveness ratings & $2 \%$ & $4 \%$ & $4 \%$ & - \\
\hline
\end{tabular}

nal, numerous reversals were found, with the greatest percentages occurring for attractiveness ratings versus prices $(27 \%)$. Below the diagonal, the rate of reversals was zero (rounded to the nearest 1\%) for all six pairs of tasks.

Because each subject performed all four tasks, it was possible to examine preference reversals at the individual subject level. Table 3 presents medians of individual subject preference reversals. Individual reversals were similar to those found in the aggregate data, although the rate of reversals above the diagonal was slightly reduced. For each subject, the percentage of preference reversals above the diagonal was compared to the corresponding percentage below the diagonal. For five of the six pairs of tasks, the majority of individuals had significantly more preference reversals above the diagonal than below.

There are interesting patterns in the derived ranks and median responses that cannot be seen by merely counting preference reversals. Figure 4 shows three distinct preference orders for median attractiveness ratings, strength-of-preference judgments, and selling prices. (Buying prices, not shown, are similar to selling prices.) The numbers 1 through 36 represent the lowest ranked to highest ranked gambles, respectively. Arrows indicate the direction of preference for gambles with equal expected values. Arrows that point up indicate a gamble pair for which the $\mathbf{P}$ Bet was ranked higher than the \$ Bet; arrows that point down indicate a gamble pair for which the $\$$ Bet was ranked higher than the P Bet. Double lines indicate ties.

For attractiveness ratings, all arrows point up; $P$ Bets were more attractive than $\$$ Bets. For selling prices, all but one of the arrows point down; $\$$ Bets were worth more than P Bets. For strength of preference, the order was more complex. For higher probabilities, $\mathrm{P}$ Bets were preferred to $\$$ Bets, and for lower probabilities, $\$$ Bets were preferred to $\mathrm{P}$ Bets.

\section{Experiment 2: Financial Incentives}

One might conjecture that the results of Experiment 1 occurred because subjects were not financially motivated. If given incentives, subjects might make fewer reversals. Pre-

\footnotetext{
${ }^{3}$ All tests were done with a chi-square statistic with 1 degree of freedom and an alpha level of .01. For each pair of tasks, A and B, the number of times the $P$ Bet was ranked higher than the $\$$ Bet for Task A was compared with the number of times the $P$ Bet was ranked higher than the $\$$ Bet for Task B. Expected proportions for the two cells were assumed to be equal and were estimated from the average of the two observed frequencies.
} 
ATTRACTIVENESS

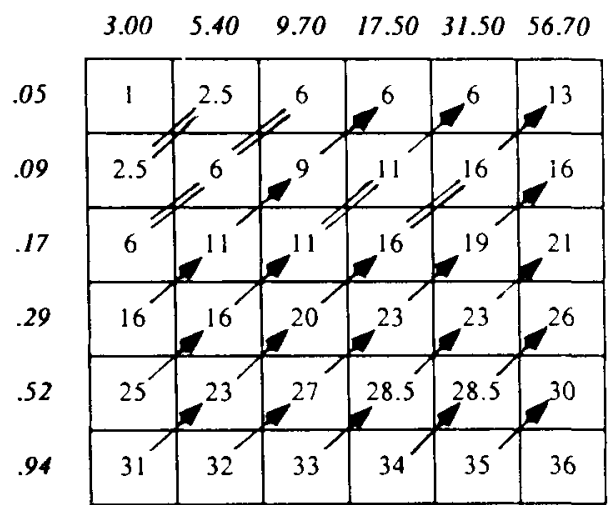

STRENGTH OF PREFERENCE

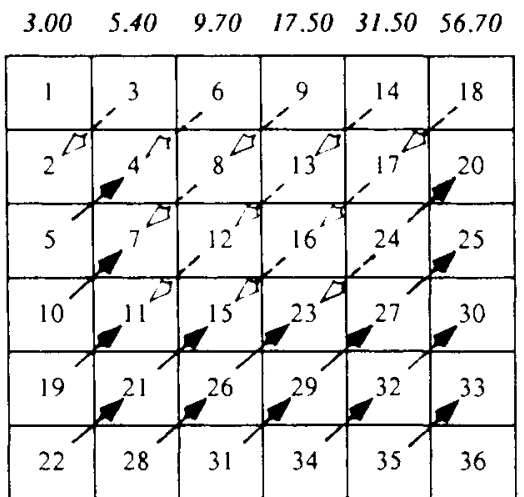

SELLING PRICE

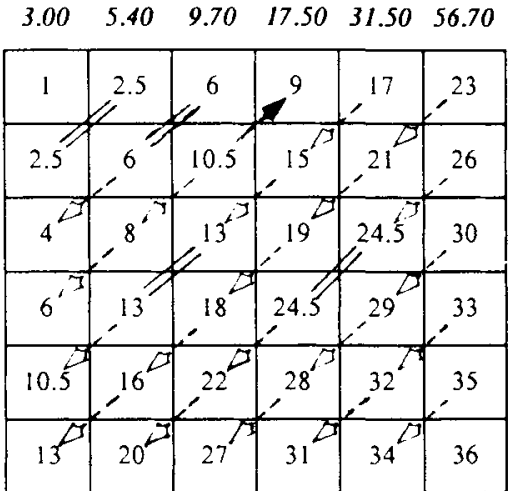

Figure 4. Preference orders for attractive ratings, strength-of-preference judgments, and selling prices. (For ratings and prices, rank orders are obtained directly from median responses. For strength-ofpreference judgments, orders are derived from medians. Larger numbers refer to higher ranked gambles. Arrows show the direction of preference for sequential gamble pairs with equal expected values. Arrows pointing up indicate gamble pairs for which the $\mathrm{P}$ Bet was ranked higher than the $\$$ Bet; arrows pointing down show pairs for which the $\$$ Bet was ranked higher than the P Bet. Double lines represent ties.)

vious studies that investigated financial incentives found similar rates of preference reversals with and without incentives (Grether \& Plott, 1979; Lichtenstein \& Slovic, 1973; Reilly, 1982; Tversky et al., 1990). Because the present results not only demonstrate reversals of preference but also provide evidence against other theories of preference reversals, it is important to investigate whether preference orders can be altered with financial incentives using the same experimental design.

Figure 5 presents median responses and derived ranks for financially motivated subjects in Experiment 2. Responses and ranks are similar to those found in Experiment 1 (see

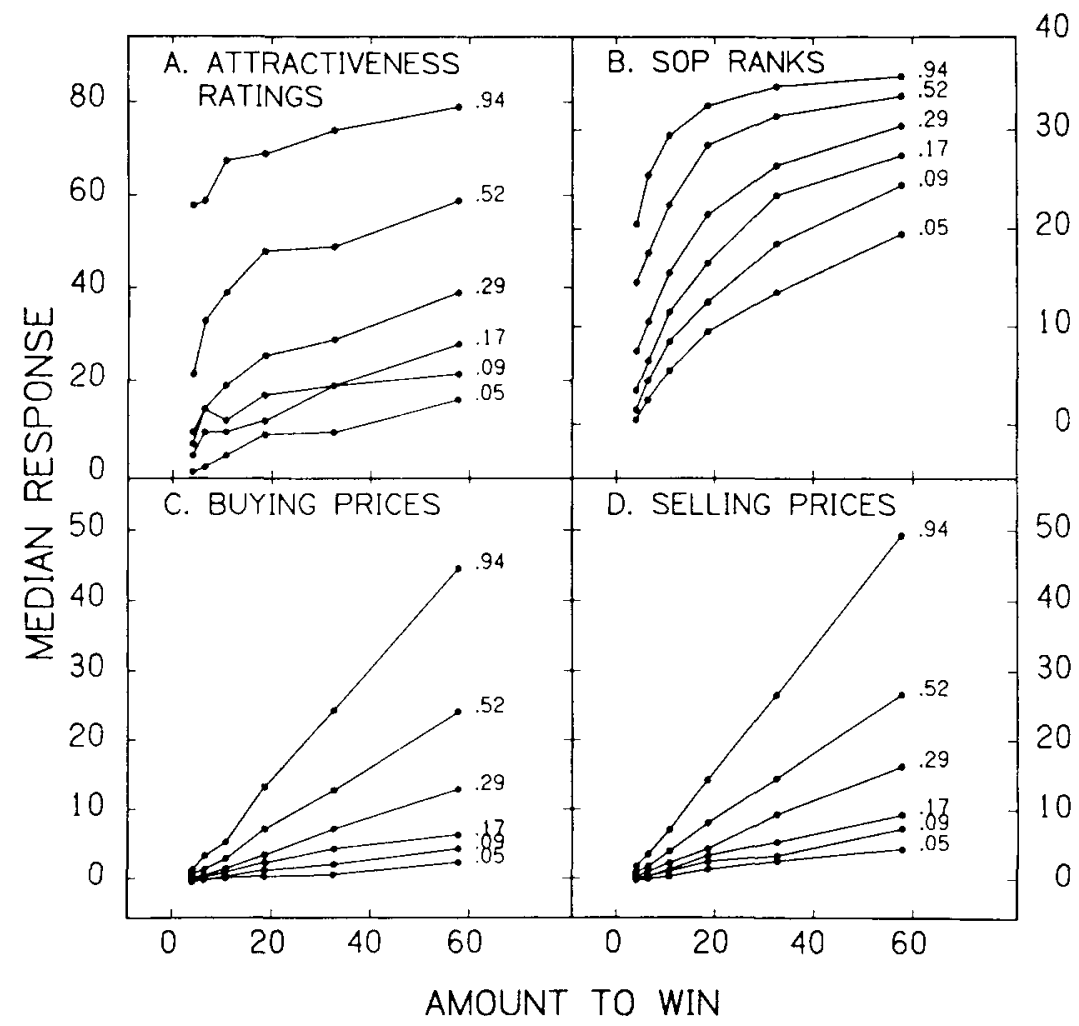

Figure 5. Median responses and ranks, plotted as in Figure 3, for the results from Experiment 2, with subjects who were financially motivated to be consistent in rank order. 
Table 4

Experiment 2: Percentage of Preference Reversals for Equal Expected Value Pairs When Subjects Had Financial Incentives

\begin{tabular}{lcccc}
\hline & \multicolumn{4}{c}{ P Bet ranked higher than \$ Bet } \\
\cline { 2 - 5 } $\begin{array}{c}\text { \$ Bet ranked higher } \\
\text { than P Bet }\end{array}$ & $\begin{array}{c}\text { Selling } \\
\text { prices }\end{array}$ & $\begin{array}{c}\text { Buying } \\
\text { prices }\end{array}$ & $\begin{array}{c}\text { Strength of } \\
\text { preference }\end{array}$ & $\begin{array}{c}\text { Attractiveness } \\
\text { ratings }\end{array}$ \\
\hline Selling prices & - & $16 \%$ & $56 \%$ & $82 \%$ \\
Buying prices & $0 \%$ & - & $25 \%$ & $64 \%$ \\
Strength of preference & $0 \%$ & $5 \%$ & - & $42 \%$ \\
Attractiveness ratings & $0 \%$ & $2 \%$ & $0 \%$ & - \\
\hline
\end{tabular}

Note. Counts are based on median responses.

Figure 3). Financial incentives did not appear to change the patterns of the curves in Experiment 2.

Table 4 lists percentages of preference reversals. The percentage of preference reversals above the diagonal was significantly greater than the corresponding percentage below the diagonal for all six pairs of tasks. Preference reversals with financially motivated subjects (Table 4) occurred at approximately the same rate as those found with financially unmotivated subjects in Experiment 1 (Table 2). Interestingly, some pairs of tasks had slightly more reversals (e.g., $64 \%$ vs. $44 \%$ with attractiveness ratings and buying prices), whereas others had slightly fewer. Table 5 presents median percentages of preference reversals for individual subjects. These percentages resemble individual subject data in Table 3 (Experiment 1) without financial incentives.

Experiment 2 showed that it was possible to replicate the results of Experiment 1 with a new group of subjects who were financially motivated. Preference orders for the financially motivated subjects in Experiment 2 were virtually identical to those found in Experiment 1 (Figure 4).

\section{Experiment 3: Domain of Losses}

Figure 6 displays median responses and ranks for Experiment 3. Data are plotted as a function of the amount to lose, with a separate curve for each probability of losing. Unattractiveness ratings and risk ratings in Panels $\mathrm{A}$ and $\mathrm{B}$ of Figure 6 are nearly parallel. Panel $C$ of Figure 6 shows the rank order derived from median strength-of-preference judgments. Ranks have been inverted for ease of comparison with previous figures: 1 is the most preferred gamble, and 36 is the least preferred gamble. Panel D of Figure 6 plots avoidance prices that form a bilinear fan, which is consistent with the pricing tasks in Figures 3 and 5.

Preference reversals for gamble pairs with equal expected values are shown in Table 6. Percentages are based on median responses. Entries represent the percentage of gamble pairs for which the P Bet was ranked lower (rated more unattractive, received a larger avoidance price, or was less preferred) in the column task, and the $\$$ Bet was ranked lower in the row task. The $P$ Bet was rated more unattractive than the $\$$ Bet, and subjects paid more to avoid playing the $\$$ Bet in $73 \%$ of the gamble pairs. In $55 \%$ of the pairs, the P Bet was less preferred than the $\$$ Bet, and subjects paid more to avoid the $\$$ Bet than the $\mathrm{P}$ Bet. Preference reversals below the diagonal were rare and ranged from $0 \%$ to $2 \%$.

Once again, individual subject rates of preference reversals were fairly similar to the aggregate rates. Table 7 shows median percentages of individual reversals for gambles with equal expected values. For the majority of subjects, there were significantly more preference reversals above the diagonal than below the diagonal for all three pairs of tasks.

Figure 7 displays preference orders of median unattractiveness ratings, strength-of-preference judgments, and avoidance prices. (Risk ratings, not shown, have virtually the same rank order as unattractiveness ratings.) Recall that numbers have been reflected to facilitate comparison with Figure 4: 1 is the most preferred gamble, and 36 is the least preferred gamble. Arrows point in the direction of the less-preferred gamble. Arrows that point up show where the $P$ Bet was less preferred than the \$Bet. Arrows that point down show where the \$Bet was less preferred than the P Bet. Double lines represent ties.

In the rating task, all but one arrow points up: $P$ Bets were more unattractive than $\$$ Bets. In the pricing task, all but one of the arrows point down; subjects paid more to avoid $\$$ Bets than P Bets. For strength of preference, arrows go in both directions. For smaller probabilities of a loss, $\$$ Bets were less preferred than $\mathrm{P}$ Bets. For larger probabilities, P Bets were less preferred than $\$$ Bets. The resemblance between the preference orders in Experiment 1 (Figure 4) and Experiment 3 (Figure 7) is striking. Preference orders for losses tend to be the mirror image of those found with gains.

\section{Strength-of-Preference Judgments}

Weak, moderate, and strong transitivity were tested for strength-of-preference judgments by identifying all possible triplets of the form $S(i, j), S(j, k)$, and $S(i, k)$. The experimental design allowed 400 triplets. Median strength-of-preference judgments in all three experiments contained few violations of weak transitivity $(2 \%, 2 \%$, and $0 \%$ in Experiments 1,2 , and 3 ) or moderate transitivity (4\%, $7 \%$, and $4 \%$ ). Strong transitivity violations were considerably more frequent $(32 \%, 36 \%$, and $23 \%)$. Individual violations were similar to those found in the aggregate data and are shown in Table 8. Median percentages of individual strong transitivity violations were $48 \%, 48 \%$, and $58 \%$.

Violations of strong transitivity do not depend on the use of rating scales instead of choice proportions. When strengthof-preference judgments were transformed to binary responses

Table 5

Experiment 2: Median Percentage of Preference Reversals for Individual Subjects With Financial Incentives

\begin{tabular}{lcccc}
\hline & \multicolumn{4}{c}{ P Bet ranked higher than \$ Bet } \\
\cline { 2 - 5 } $\begin{array}{c}\text { \$ Bet ranked higher } \\
\text { than P Bet }\end{array}$ & $\begin{array}{c}\text { Selling Buying } \\
\text { prices }\end{array}$ & $\begin{array}{c}\text { Strength of } \\
\text { prices }\end{array}$ & $\begin{array}{c}\text { Attractiveness } \\
\text { preference }\end{array}$ & \begin{tabular}{c} 
ratings \\
\hline Selling prices
\end{tabular} \\
Buying prices & - & $11 \%$ & $22 \%$ & $45 \%$ \\
Strength of preference & $5 \%$ & $7 \%$ & - & $29 \%$ \\
Attractiveness ratings & $2 \%$ & $4 \%$ & $4 \%$ & - \\
\hline
\end{tabular}




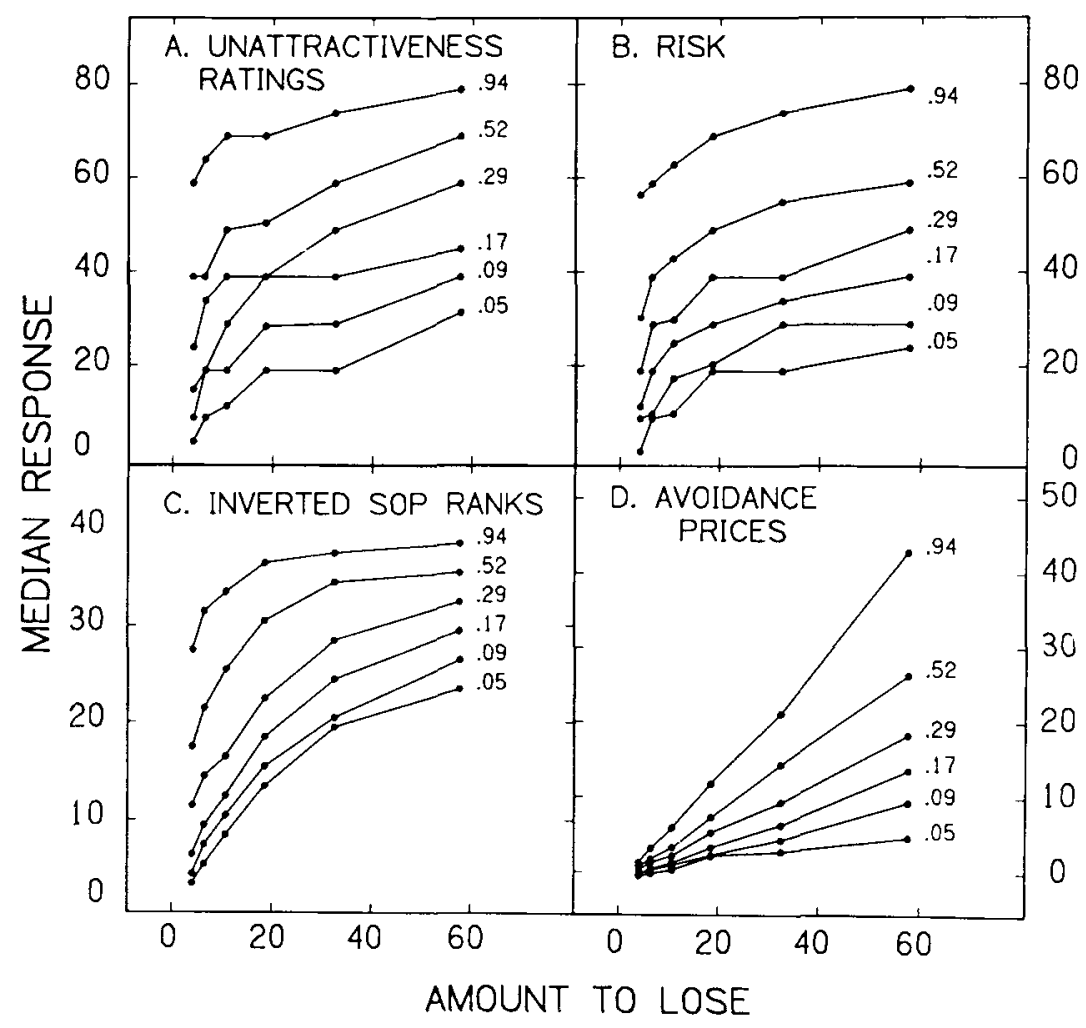

Figure 6. Median responses and ranks from Experiment 3. (Values are plotted as a function of the amount to lose, with a separate curve for each probability of losing. Panels A and B show median unattractiveness ratings and risk ratings, respectively. Panel $C$ presents the rank order of gambles inferred from median strength-of-preference judgments. Numbers 1 and 36 now refer to the best and worst gambles, respectively, to facilitate comparison with Figure 3. Panel D shows avoidance prices.)

and converted to choice proportions, there were $44 \%, 49 \%$, and $64 \%$ violations of strong stochastic transitivity in Experiments 1, 2, and 3, respectively. Moderate stochastic transitivity violations were much less frequent $(4 \%, 8 \%$, and $8 \%)$, and weak stochastic transitivity violations were negligible $(2 \%$, $2 \%$, and $2 \%$ ).

Is there a systematic pattern in the triplets that violates strong transitivity? An examination of the triplets that did and did not produce violations shows that violations tend to occur in triplets in which at least one gamble pair had a small contrast along one dimension and a larger contrast on the other. Perhaps when levels along a dimension are close (i.e., either probabilities or amounts are similar), differences on the

Table 6

Experiment 3: Percentage of Preference Reversals for Equal Expected Value Pairs in the Domain of Losses

\begin{tabular}{lccc}
\hline \multirow{2}{*}{$\begin{array}{c}\text { B Bet ranked lower } \\
\text { than P Bet }\end{array}$} & \multicolumn{3}{c}{ P Bet ranked lower than \$ Bet } \\
\cline { 2 - 4 } & $\begin{array}{c}\text { Avoidance } \\
\text { prices }\end{array}$ & $\begin{array}{c}\text { Strength of } \\
\text { preference }\end{array}$ & $\begin{array}{c}\text { Unattractiveness } \\
\text { ratings }\end{array}$ \\
\hline $\begin{array}{l}\text { Avoidance prices } \\
\text { Strength of preference }\end{array}$ & - & $55 \%$ & $73 \%$ \\
Unattractiveness ratings & $0 \%$ & - & $29 \%$ \\
\hline
\end{tabular}

Note. Counts are based on median responses. other dimension are enhanced, causing violations of strong transitivity.

Consider these three gambles with equal expected values: Gamble $i$ is a .52 chance of winning $\$ 3$, gamble $j$ is a .05 chance of winning $\$ 31.50$, and gamble $k$ is a .09 chance of winning $\$ 17.50$. Subjects in Experiment 1 preferred $i$ to $j, j$ to $k$, and $i$ to $k$, which satisfies weak transitivity. The median strength-of-preference judgments were $S(i, j)=10, S(j, k)=$ 22 , and $S(i, k)=12.52 \%$ of individual subjects displayed this pattern. Strong transitivity implies that $S(i, k)$ should have been greater than or equal to 22 . Either $S(i, k)$ was too small (10) or $S(j, k)$ was too large (22). Gambles $j$ and $k$ have a small difference in probabilities and differ more in amounts. Similar patterns were found when gamble pairs within a triplet

Table 7

Experiment 3: Median Percentage of Preference Reversals for Individual Subjects in the Domain of Losses

\begin{tabular}{lccc}
\hline \multirow{2}{*}{$\begin{array}{c}\text { \$ Bet ranked lower } \\
\text { than P Bet }\end{array}$} & \multicolumn{3}{c}{ P Bet ranked lower than \$ Bet } \\
\cline { 2 - 4 } & $\begin{array}{c}\text { Avoidance } \\
\text { prices }\end{array}$ & $\begin{array}{c}\text { Strength of } \\
\text { preference }\end{array}$ & $\begin{array}{c}\text { Unattractiveness } \\
\text { ratings }\end{array}$ \\
\hline Avoidance prices & - & $38 \%$ & $42 \%$ \\
Strength of preference & $2 \%$ & - & $20 \%$ \\
Unattractiveness ratings & $0 \%$ & $5 \%$ & - \\
\hline
\end{tabular}



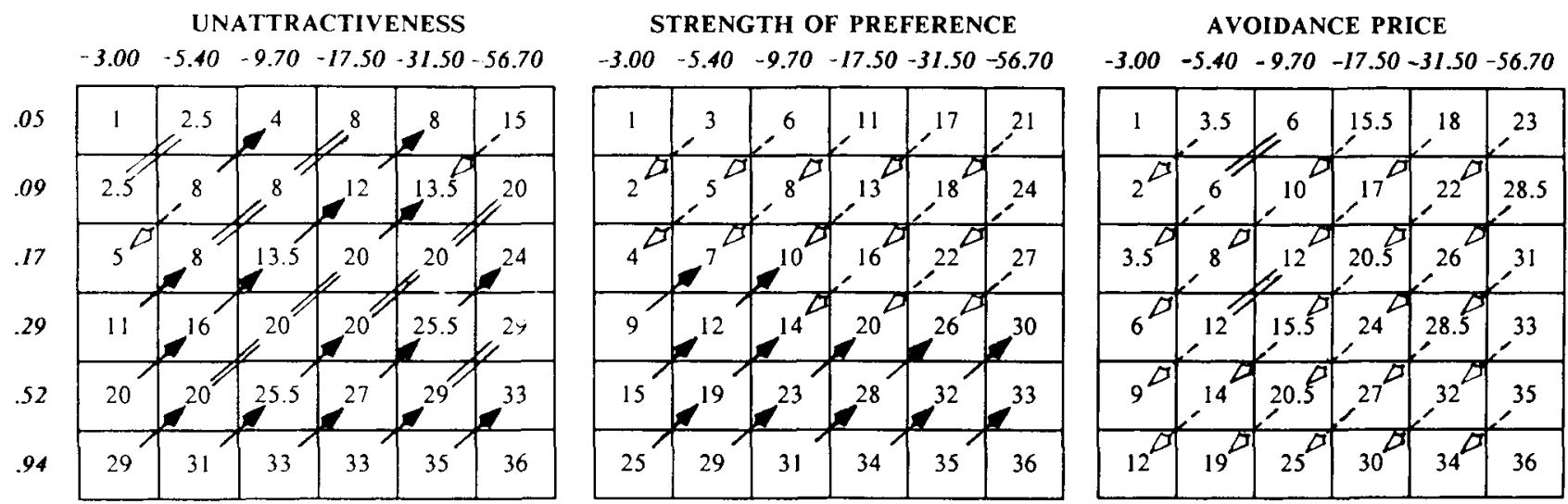

Figure 7. Preference orders for unattractive ratings, strength-of-preference judgments, and avoidance prices. (Number 1 refers to the most preferred gamble, and Number 36 refers to the least preferred gamble. For ratings and prices, rank orders are obtained directly from median responses. For strengthof-preference judgments, orders are inferred from medians to satisfy weak transitivity. Arrows pointing up indicate gamble pairs for which the $\mathrm{P}$ Bet is considered worse than the $\$$ Bet; arrows pointing down show pairs for which the $\$$ Bet is considered worse than the P Bet. Double lines represent ties.)

had small differences in amounts and greater differences in probabilities. Similar patterns also occurred in the domain of losses. Violations of strong transitivity are inconsistent with Equation 3 but might be described by the contrast-weighting model (Equation 4).

\section{Fit of the Change-of-Process Theory}

The present experiments provide an opportunity to investigate whether the change-of-process theory can be extended to account for strength-of-preference judgments. In particular, can attractiveness ratings be described by the additive model, prices by the multiplicative model, and strength-of-preference judgments by the contrast-weighting model, with the same utilities and subjective probabilities in all four tasks?

There are two ways to fit change-of-process theory to data from the four tasks. One method is to fit models separately to results from each task, compare observed ranks with predicted ranks, examine the patterns of residuals in the numerical values, and consider the separate lack-of-fit indexes. Another method is to fit simultaneously all four models to the data and force the scales to be independent of the task. By comparing the two analyses, one can ask whether the assumption of scale convergence is satisfied. When scales are allowed to differ, are preference ranks significantly better predicted than when scales are forced to converge? When scales are allowed to differ, is the agreement of predictions and data noticeably better than when scales are forced to be invariant? ${ }^{4}$

Domain of gains. All four models were fit separately to medians from the four tasks in Experiment 1 by means of a Fortran program that used Chandler's (1969) STEPIT subroutine for minimization. For each task, the following loss index, $L_{\mathrm{I}}$, was minimized:

$$
L_{\mathrm{T}}=\Sigma(X-\hat{X})^{2} /(X-\bar{X})^{2}
$$

where $X$ is the median, $\hat{X}$ is the prediction, $\bar{X}$ is the grand mean within a task, and the summation is over all gambles (or pairs of gambles) in the design. $L_{\mathrm{T}}$ represents the percentage of residual variance in task $T$.

Attractiveness ratings were fit to an additive model (Equation 1), which required the estimation of the subjective probabilities, $s(p)$, the scaling constant, $k$, the utilities, $u(x)$, and a judgment function, $J_{\mathrm{A}}$. The $J_{\mathrm{A}}$ function was assumed to be linear.

Buying and selling prices were fit to a special case of the multiplicative model (Equation 2). Birnbaum, Coffey, Mellers, and Weiss (1992) proposed a model of judged prices which assumes that utilities remain constant but that subjective probabilities can differ between points of view (buying vs. selling prices). The relative weights of the higher and lower valued outcomes within each gamble depend on the judge's point of view. Assuming that $u(x)=0$, their model implies that

$$
\mathrm{P}_{\mathrm{v}}(x, p ; 0)=J_{\mathrm{v}}\left[s_{\mathrm{v}}(p) \cdot u(x)\right],
$$

where $\mathrm{P}_{\mathrm{v}}(x, p ; 0)$ is the judged price when the judge's point

\footnotetext{
${ }^{4}$ One strategy for testing scale convergence is to compare the scales derived from the fit of different models without scale convergence to one another (Birnbaum, 1982); however, this test can be difficult to assess because the models have different uniqueness properties. Uniqueness refers to the class of scale transformations that preserve rank order predictions from the model. For example, scales derived from the additive model are unique to a linear transformation, and scales derived from a multiplicative model are unique to a power transformation. If scale convergence is assumed, then scales derived from the separate fits of each model could be related by a linear function of a power function, and scale convergence would still be preserved. In other words, scales need not be identical, or even linearly related, to satisfy scale convergence. Therefore, with these particular models, we use the strategy of fitting the models with and without the constraint of common scales to test the assumption of scale convergence.
} 
Table 8

Median Percentage of Transitivity Violations for Individual Subjects

\begin{tabular}{|c|c|c|c|c|c|c|}
\hline \multirow[b]{3}{*}{ Experiment } & \multicolumn{6}{|c|}{ Strength-of-preference judgments } \\
\hline & \multicolumn{2}{|c|}{ Weak } & \multicolumn{2}{|c|}{ Moderate } & \multicolumn{2}{|c|}{ Strong } \\
\hline & Median & Range & Median & Range & Median & Range \\
\hline 1 & & & & & & \\
\hline${ }_{2}$ Gains & $3 \%$ & $0 \%-13 \%$ & $20 \%$ & $0 \%-41 \%$ & $48 \%$ & $11 \%-82 \%$ \\
\hline${ }_{3}$ Financial incentives & $3 \%$ & $0 \%-21 \%$ & $19 \%$ & $0 \%-51 \%$ & $48 \%$ & $0 \%-76 \%$ \\
\hline Losses & $4 \%$ & $0 \%-12 \%$ & $21 \%$ & $7 \%-38 \%$ & $58 \%$ & $26 \%-69 \%$ \\
\hline
\end{tabular}

Note. Percentages are based on 400 triplets for each subject.

of view is $\mathrm{V}$, and $s_{\mathrm{V}}(p)$ is the subjective weight of the higher valued outcome. This subjective weight can be written as

$$
s_{\mathrm{V}}(p)=a_{\mathrm{V}} s(p) /\left[a_{\mathrm{V}} s(p)+\left(1-a_{\mathrm{V}}\right)(1-s(p))\right] .
$$

Changes in point of view are represented by means of a single parameter, $a_{\mathrm{V}}$, which indicates the relative weight of higher versus lower valued outcomes. ${ }^{5}$ Mellers et al. (in press) did not manipulate point of view and set $a_{\mathrm{v}}$ to .5 , resulting in $s_{\mathrm{V}}(p)=s(p)$. In the present experiments, point of view is manipulated and $a_{\mathrm{V}}$ is estimated by using Equations 6 and 7 .

The $J_{\mathrm{v}}$ function in Equation 6 was approximated by the power function, $\mathrm{P}_{\mathrm{v}}=d\left[s_{\mathrm{v}}(p) u(x)\right]^{e}$, where $d$ and $e$ are a multiplicative constant and exponent. These parameters were assumed to be the same for buying and selling prices. If prices are interpreted as certainty equivalents, and utilities are described by a power function, then the exponent is the reciprocal of the exponent in the power function for utility.

Strength-of-preference judgments were fit to the contrastweighting model (Equation 4). Subjective probabilities, utilities, weights, a scaling constant, and a judgment function (approximated by a cubic polynomial) were estimated. Weights, $\alpha_{i j}$ and $\beta_{i j}$, were assumed to have two levels. When levels of amount were adjacent and differed by less than $\$ 10$, they received one value of $\alpha_{i j}$; all other pairs of amounts received the other value. When levels of probability were adjacent and differed by less than .20 , they were given one value of $\beta_{i j}$; all other pairs were assigned the other value.

When the four models (Equation 1 for attractiveness ratings, Equation 4 for strength of preference, and two versions of Equation 6 with a different parameter for buying and selling prices) were fit separately (i.e., without the assumption of scale convergence), the percentage of residual variance was $1 \%$ or less for attractiveness ratings, buying prices, and selling prices, and $5 \%$ for strength-of-preference judgments. (Strength-of-preference judgments have 225 responses, compared with 36 responses in each of the other three tasks.) The sum of the four lack-of-fit indexes was 7\%. Estimated weights for strength-of-preference judgments were .10 and .29 for small and large probability differences, respectively. Estimated weights for small and large amount differences were .23 and .31 , respectively. Values were consistent with the hypothesis that smaller contrasts receive smaller weights.

To investigate the assumption of scale convergence, all four models were fit simultaneously to data from the four tasks; utilities and subjective probabilities were constrained to be same. The lack-of-fit index was computed for each task, and the sum of the four indexes was minimized.

The percentage of residual variance was approximately $1 \%$ for attractiveness ratings, buying prices, and selling prices, and $5 \%$ for strength-of-preference judgments. The sum of the four lack-of-fit indexes was $9 \%$ (compared with $7 \%$ when scales were allowed to differ). Thus, the lack of fit did not appear to increase substantially when scales were constrained to be the same across tasks.

Figure 8 shows predicted preference orders for the changeof-process theory. With a few exceptions, all three predicted orders resemble the observed orders in Figure 4. Different preference orders could be described by the theory, which assumes that decision strategies differ but scales remain constant.

The change-of-process theory could account for the frequencies of transitivity violations found in strength-of-preference judgments. Predicted violations of weak, moderate, and strong transitivity were $0 \%, 6 \%$, and $31 \%$, respectively. Observed violations were $2 \%, 4 \%$, and $32 \%$, respectively.

Estimated utilities were a concave downward function of money. (Values were 3, 4.5, 7.1, 11.7, 17.2, and 24.6, where 3 was fixed to the physical amount.) Subjective probabilities were also a concave downward function of objective probability. (Values were $.17, .21, .27, .39, .60$, and .94 , where .94 was fixed.) Values of $a_{\mathrm{v}}$ were .46 and .63 for buying and selling prices, respectively. Larger values of $a_{\mathrm{V}}$ indicate greater weight on the higher valued outcome (see Footnote 5), so these values are compatible with those found by Birnbaum et al. (1992). The scaling constant, $k$, was 101. Estimated weights for strength-of-preference judgments were .11 and .32 for small and large probability differences and .12 and .20 for small and large amount differences, respectively.

Domain of losses. The same procedure was followed as in the domain of gains. Unattractiveness ratings and risk ratings

\footnotetext{
${ }^{5}$ Birnbaum, Coffey, Mellers, and Weiss (1992) wrote their model in a different form. In Equation $7, P, s(p), s_{V}(p)$, and $a_{\mathrm{V}}$ are associated with the higher valued outcome, whereas Birnbaum et al. (1992) used similar notation for the lower valued outcome. Both the present results and those of Birnbaum et al. demonstrate greater weighting of the lower valued outcome from the buyer's point of view.
} 
ATTRACTIVENESS

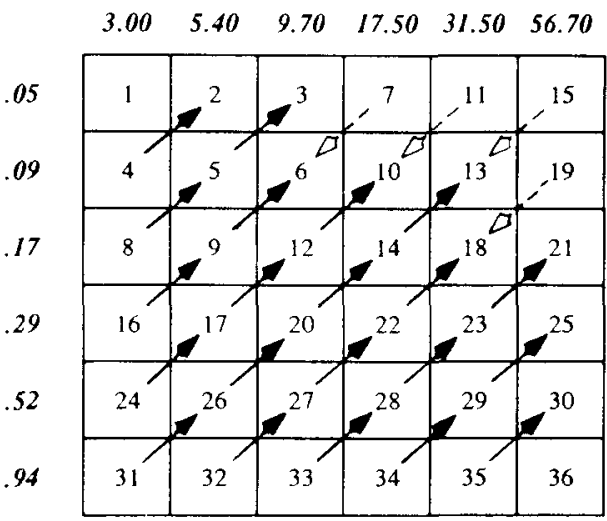

STRENGTH OF PREFERENCE

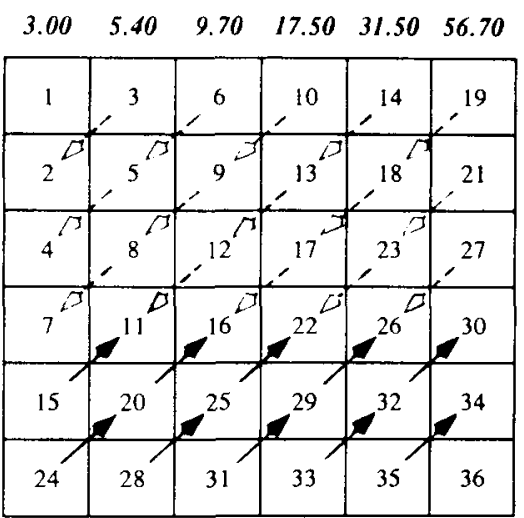

SELLING PRICE

$\begin{array}{llllll}3.00 & 5.40 & 9.70 & 17.50 & 31.50 & 56.70\end{array}$

\begin{tabular}{|c|c|c|c|c|c|}
\hline 1 & 3 & 8 & 14 & 19 &, 24 \\
\hline 2 & 5 & 10 & 16 & 22 & 27 \\
\hline 4 & 7 & 12 & 20 & 25 & 30 \\
\hline 6 & 11 & 17 & 23 & 29 & 33 \\
\hline 9 & 15 & 21 & 28 & 32 & 35 \\
\hline 13 & 18 & 26 & 31 & 34 & 36 \\
\hline
\end{tabular}

Figure 8. Predicted preference orders for attractiveness ratings, strength-of-preference judgments, and selling prices for the change-of-process theory (Equations 1, 4, and 7), which asserts that decision strategies change across response modes, but scales remain constant. (Predicted orders should be compared with empirical orders in Figure 4.)

were fit to the additive model (Equation 1). Avoidance prices were fit to the multiplicative model (Equation 6), and strength-of-preference judgments were fit to the contrastweighting model (Equation 4).

The percentage of residual variance in the separate models without scale convergence was $2 \%$ for unattractiveness ratings, $1 \%$ or less for risk and avoidance prices, and $9 \%$ for strength-of-preference ratings. The sum of the four lack-of-fit indexes was $12 \%$.

When scales were forced to be same, the percentage of residual variance was approximately $4 \%$ for unattractiveness ratings, $2 \%$ for risk and avoidance prices, and $10 \%$ for strength-of-preference judgments. The sum of the four lackof-fit indexes was $18 \%$ (compared with $12 \%$, without scale convergence). Although the lack of fit increased, deviations did not appear to be systematic.

Figure 9 shows that predicted preference orders resemble the observed orders in Figure 7 . Thus, despite deviations in the lack-of-fit index, the different preference orders for losses can be described by the change-of-process theory assuming scale convergence.

Predicted violations of weak, moderate, and strong transitivity were $0 \%, 4 \%$, and $27 \%$, respectively. Observed violations were $0 \%, 4 \%$, and $23 \%$, respectively.

Estimated scales for disutilities were a concave downward function of increasing loss. (Values were 3, 4.0, 5.4, 8.1, 11.2, and 15.8 , with 3 fixed to its physical amount.) Subjective probabilities were also a concave downward function of objective probability. (Values were $.47, .51, .55, .63, .75$, and .94 , with .94 fixed.) Neither disutilities nor subjective probabilities were negative; the judgment function was assumed to be a monotonically decreasing function of preference. The scaling constant, $k$, was 54 , and $a_{\mathrm{V}}$ was .42 . Estimated weights for strength-of-preference judgments were .01 and .19 for small and large probability differences and .04 and .07 for small and large amount differences, respectively.
UNATTRACTIVENESS

$-3.00-5.40-9.70-17.50-31.50-56.70$

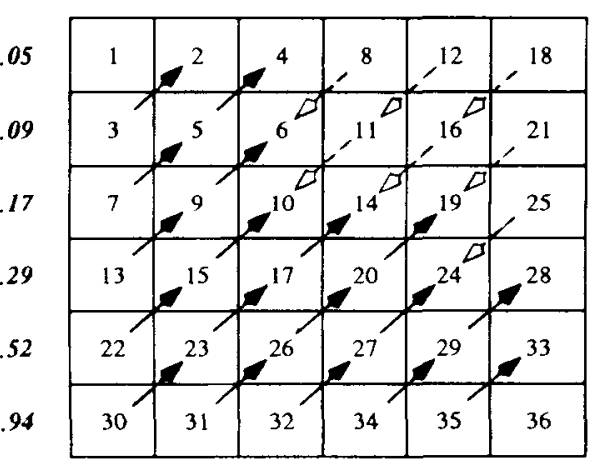

STRENGTH OF PREFERENCE

$-3.00-5.40-9.70-17.50-31.50-56.70$

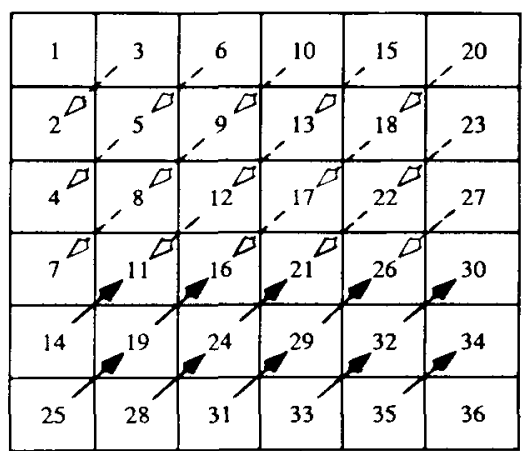

AVOIDANCE PRICE

\begin{tabular}{|r|r|r|r|r|r|}
\hline-3.00 & -5.40 & -9.70 & $-17.50-31.50$ & -56.70 \\
\hline 1 & 4 & 9 & 16 & 21 &, 27 \\
\hline 2 & 6 & 11 & 17 & 23 & 29 \\
\hline 3 & 7 & 12 & 20 & 25 & 31 \\
\hline 5 & 10 & 15 & 22 & 28 & 33 \\
\hline 8 & 13 & 19 & 26 & 32 & 35 \\
\hline 14 & 18 & 24 & 30 & 34 & 36 \\
\hline
\end{tabular}

Figure 9. Predicted orders for unattractiveness ratings, strength-of-preference judgments, and avoidance prices for the change-of-process theory (Equations 1, 2, and 4), which asserts that decision strategies change across response modes, but scales remain constant. (Predicted orders should be compared with empirical orders in Figure 7.) 


\section{Discussion}

\section{Psychological Theories of Preference Reversals}

The present experiments are compatible with previous research that favored the change-of-process theory as an explanation of preference reversals. According to this theory, preference reversals are due to changing decision strategies, but utilities remain constant across tasks. Present data show that the change-of-process theory can be extended successfully to unattractiveness ratings, risk ratings, selling prices, avoidance prices, and strength-of-preference judgments.

\section{Risk and Attractiveness Ratings}

The parallelism of the curves in Figures 3, 5, and 6 is consistent with an additive combination of utilities and subjective probabilities. Levin, Johnson, Russo, and Delden (1985) also found parallel curves when they plotted attractiveness ratings of gambles as a function of the probability of winning (or losing) with a separate curve for each amount to win (or lose). Additive models for risk ratings have been considered by Payne (1973), but most theories assume a multiplicative relationship between probability and amount (Coombs \& Lehner, 1984; Fishburn, 1982, 1984). Other theories of risk (Luce \& Weber, 1986; Weber, Anderson, \& Birnbaum, in press) involve configural weighting of outcomes by functions of probabilities that also depend on the rank or the sign of the outcome.

The additive model of attractiveness ratings may seem peculiar, considering it makes implausible predictions when probabilities and amounts approach zero. The additive model implies that if subjects were shown a gamble (or a pair of gambles) with zero probabilities of winning varying amounts, the attractiveness rating should increase as the amount increased. It seems reasonable to suppose that if subjects were presented with such combinations, they might change their strategy.

This implication was tested by Mellers et al. (in press) for attractiveness ratings. When zero and near-zero values of probability and amount were included in the stimulus design, the majority of subjects made attractiveness ratings that switched from a parallel pattern to a bilinear pattern. The bilinear pattern also had a different preference order, which is consistent with the theory that the model changed from additive to multiplicative. Similar results were found with risk ratings (Mellers \& Chang, in press).

Certain stimuli may offer feedback to the subjects about their decision strategy and thereby guide them toward another strategy. Mellers et al. (in press) concluded that changes in the stimulus context, as well as changes in the response mode, can influence the rank order of gambles. This result fits well within a change-of-process framework but is difficult to explain by contingent weighting theory (Tversky et al., 1988) or expression theory (Goldstein \& Einhorn, 1987).

Weber et al. (in press) examined risk and attractiveness ratings with a wide range of gambles having from two to five outcomes. They concluded that probabilities and amounts combined multiplicatively, but outcomes were averaged to form risk and attractiveness ratings. Although there are several differences between the present experiments and those of Weber et al., the two sets of results are compatible with the idea that decision strategies depend on the context formed by the other gambles in the experiment.

\section{Prices}

In the present experiments, buying, selling, and avoidance prices were consistent with multiplicative combination rules. Preference orders that were based on a Probability $\times$ Amount design were quite similar for buying and selling prices, although buying prices were lower than selling prices. Birnbaum et al. (1992) and Birnbaum and Sutton (in press) also found that buyer's prices tended to be lower than seller's prices. In addition, they found that the rank order of gambles in an Outcome $\times$ Outcome design varied systematically from the buyer's to the seller's point of view, a result that was not tested in the present experiments.

Birnbaum et al. (1992) and Birnbaum and Sutton (in press) concluded that buyer's and seller's prices could be described by a configural-weight model in which utilities remain constant, but subjective weights depend on the ranks of the outcomes within a gamble and the judge's point of view. Buyers assign relatively greater weight to the lowest outcome in the gamble, whereas sellers assign relatively greater weight to higher valued outcomes (Birnbaum \& Stegner, 1979; Birnbaum \& Sutton, in press). Assumptions of configural-weight theory were incorporated into the change-of-process theory for buying and selling prices, and the present results were consistent with the configural-weight theory.

\section{Strength of Preference}

In the present experiments with nondominated, binary gambles, strength-of-preference judgments could be approximated by a model in which gambles are represented by a multiplicative combination of utilities and subjective probabilities. Comparisons between gambles are represented by subtraction. Utilities and subjective probabilities are weighted according to the difference between the gambles on each dimension. When utilities (or subjective probabilities) for the two gambles are nearly equal, they received less weight than utilities (or subjective probabilities) that differed. The discounting of dimensions may be a consequence of the subject's attempt to simplify the task by reducing attention given to dimensions that show little contrast between the choices.

It seems reasonable to theorize that contrasts might be context-dependent. A given stimulus difference may appear large in one context but small in another. It would be interesting to explore what happens when subjects compare dominated gambles with identical levels of probabilities or amounts. Such contrasts have the potential to provide scalefree tests of rival algebraic models (Birnbaum, 1982).

The contrast-weighting model allows violations of transitivity in strength-of-preference judgments. In the present experiments, the contrast-weighting model predicted no violations 
of weak transitivity, minimal violations of moderate transitivity, and frequent violations of strong transitivity, which is consistent with the data.

The contrast-weighting model should not be confused with configural-weight or contingent weighting theories. In contingent weighting theory, weights are assumed to depend on the compatibility between the stimulus information and the response scale. In configural-weight theory, the weight of an outcome depends on its rank within the gamble. Distinctions between contingent weighting theory and configural-weight theory are discussed in Mellers et al. (in press) and Birnbaum et al. (in press). In the contrast-weighting model, weights along a dimension are assumed to depend on the difference between stimulus values for each pair of gambles. When stimulus values differ, they tend to receive more weight.

\section{Conclusions}

Different preference orders were obtained when subjects used different procedures to evaluate the worth of gambles. Even when subjects were financially motivated to be consistent, different preference ranks were found. Results were compatible with the theory that people use different decision strategies for combining information. In these experiments, risk and attractiveness ratings could be described by an additive combination of utility and subjective probability. Prices could be described by a multiplicative combination. Strengthof-preference judgments could be represented by a contrastweighting model in which a stimulus dimension is weighted according to the difference between gambles along that dimension, and the weighted products are compared by subtraction. Small differences receive less weight than large differences. Data from all three experiments could be described by a change-of-process theory that attributes preference reversals to variations in combination rules, whereas utilities remain constant across tasks.

\section{References}

Bernoulli, D. (1954). Exposition of a new theory on the measurement of risk. Econometrica, 22, 23-36. (Original work published 1738)

Birnbaum, M. H. (1974). The nonadditivity of personality impressions. Journal of Experimental Psychology Monograph, 102, 543561 .

Birnbaum, M. H. (1982). Controversies in psychological measurement. In B. Wegener (Ed.), Social attitudes and psychophysical measurement (pp. 401-485). Hillsdale, NJ: Erlbaum.

Birnbaum, M. H., Coffey, G., Mellers, B., \& Weiss, R. (1992). Utility measurement: Configural-weight theory and the judge's point of view. Journal of Experimental Psychology: Human Perception and Performance, 18, 331-346.

Birnbaum, M. H., \& Stegner, S. E. (1979). Source credibility in social judgment: Bias, expertise, and the judge's point of view. Journal of Personality and Social Psychology, 37, 48-74.

Birnbaum, M. H., \& Sutton, S. E. (in press). Scale convergence and utility measurement. Organizational Behavior and Human Decision Processes.

Birnbaum, M. H., \& Veit, C. T. (1974). Scale convergence as a criterion for rescaling: Information integration with difference, ratio, and averaging tasks. Perception \& Psychophysics, 15, 7-15.
Bostic, R., Herrnstein, R. J., \& Luce, R. D. (1990). The effect on the preference-reversal phenomenon of using choice indifferences. Journal of Economic Behavior and Organization, 13, 193-212.

Busemeyer, J. R. (1985). Decision making under uncertainty: A comparison of simple scalability, fixed-sample, and sequentialsample models. Journal of Experimental Psychology: Learning, Memory, and Cognition, 11, 538-564.

Busemeyer, J., \& Goldstein, W. (in press). Linking together different measures of preference: A dynamic model of matching derived from decision field theory. Organizational Behavior and Human Decision Processes.

Chandler, J. D. (1969). Subroutine STEPIT: Finds local minima of a smooth function of several parameters. Behavioral Science, 14, 81 82.

Coombs, C. (1958). On the use of inconsistencies of preferences in psychological measurement. Journal of Experimental Psychology, $55,1-7$.

Coombs, C. (1983). Psychology and mathematics. Ann Arbor: University of Michigan Press.

Coombs, C., \& Lehner, P. E. (1984). Conjoint design and analysis of the bilinear model: An application to judgments of risk. Journal of Mathematical Psychology, 38, 1-42.

Debreu, G. (1960). [Review of Individual choice behavior: A theoretical analysis]. American Economic Review, 50, 186-188.

Fishburn, P. C. (1982). Foundations of risk measurement: II. Effects of gains on risk. Journal of Mathematical Psychology, 25, 226-242.

Fishburn, P. C. (1984). Foundations of risk measurement: I. Risk as probable loss. Management Science, 30, 396-406.

Goldstein, W., \& Busemeyer, J. (in press). The effect of "irrelevant" variables on decision making: Criterion shifts in preferential order. Organizational Behavior and Human Decision Processes.

Goldstein, W., \& Einhorn, H. (1987). Expression theory and the preference reversal phenomena. Psychological Review, 94, 236254.

Grether, D. M., \& Plott, C. (1979). Economic theory of choice and the preference reversal phenomenon. American Economic Review, $69,023-638$.

Hamm, R. M. (1979). The conditions of occurrence of the preference reversal phenomenon. Dissertation Abstracts International, 40, 5848-5849.

Holt, C. A. (1986). Preference reversals and the independence axiom. American Economic Review, 76, 508-515.

Johnson, E. J., Payne, J. W., \& Bettman, J. R. (1988). Information displays and preference reversals. Organizational Behavior and Human Decision Processes, 42, 1-21.

Karni, E., \& Safra, Z. (1987). "Preference reversal" and the observability of preferences by experimental methods. Econometrica, 55, 675-685.

Krantz, D. (1964). The scaling of small and large color differences. Unpublished doctoral dissertation, University of Pennsylvania.

Kruskal, J. B., \& Carmone, F. J. (1969). MONANOVA: A Fortran IV program for monotone analysis of variance. Behavioral Science, $14,165-166$.

Levin, I. R., Johnson, R. D., Russo, C. P., \& Delden, P. J. (1985). Framing effects in judgment tasks with varying amounts of information. Organizational Behavior and Human Decision Processes, $36,362-377$.

Lichtenstein, S., \& Slovic, P. (1971). Reversals of preferences between bids and choices in gambling decisions. Journal of Experimental Psychology, 89, 46-55.

Lichtenstein, S., \& Slovic, P. (1973). Response-induced reversals of preference in gambling: An extended replication in Las Vegas. Journal of Experimental Psychology, 101, 16-20.

Lindman, H. R. (1971). Inconsistent preferences among gambles. Journal of Experimental Psychology, 89, 390-397. 
Loomes, G. (1990). Preference reversal: Explanations, evidence, and implications. Annals of Operations Research, 23, 65-90.

Loomes, G., \& Sugden, R. (1983). A rationale for preference reversal. American Economic Review, 73, 428-432.

Luce, R. D. (1959). Individual choice behavior: A theoretical analysis. New York: Wiley.

Luce, R. D., \& Weber, E. U. (1986). An axiomatic theory of conjoint expected risk. Journal of Mathematical Psychology, 30, 188-205.

Mellers, B. A., \& Chang, S. (in press). Representations of risk judgments. Organizational Behavior and Human Decision Processes.

Mellers, B. A., Ordóñez, L., \& Birnbaum, M. (in press). A change-ofprocess theory for contextual effects and preference reversals in risky decision making. Organizational Behavior and Human Decision Processes.

Mowen, J. C., \& Gentry, J. W. (1980). Investigation of the preferencereversal phenomenon in a new product introduction task. Journal of Applied Psychology, 65, 715-722.

Payne, J. (1973). Alternative approaches to decision making under risk: Moments versus risk dimensions. Psychological Bulletin, 80 , 439-453.

Payne, J. (1976). Task complexity and contingent processing in decision making: An information search and protocol analysis. Organizational Behavior and Human Performance, 16, 366-387.

Payne, J. (1982). Contingent decision behavior. Psychological Bulle$\operatorname{tin}, 92,382-402$.

Pommerehne, W. W., Schneider, F., \& Zweifel, P. (1982). Economic theory of choice and the preference reversal phenomenon: A reexamination. American Economic Review, 72, 569-574.

Reilly, R. J. (1982). Preference reversal: Further evidence and some suggested modifications in experimental design. American Economic Review, 72, 576-584.

Restle, F. (1961). Psychology of judgment and choice. New York: Wiley.
Rumelhart, D., \& Greeno, J. (1971). Similarity between stimuli: An experimental test of the Luce and Restle choice models. Journal of Mathematical Psychology, 8, 59-108.

Sarin, R. K. (1982). Strength of preference and risky choice. Operations Research, 30, 982-997.

Schkade, D. A., \& Johnson, E. J. (1989). Cognitive processes in preference reversals. Organizational Behavior and Human Decision Processes, 44, 203-231.

Slovic, P., \& Lichtenstein, S. (1983). Preference reversals: A broader perspective. American Economic Review, 73, 596-605.

Slovic, P., \& MacPhillamy, D. (1974). Dimensional commensurability and cue utilization. Organizational Behavior and Human Performance, $11,172-194$.

Thurstone, L. L. (1927). A law of comparative judgment. Psychological Review, 34, 273-286.

Tversky, A. (1969). Intransitivity of preference. Psychological Review, $76,31-48$.

Tversky, A., \& Russo, J. (1969). Substitutability and similarity in binary choice. Journal of Mathematical Psychology, 6, 1-12.

Tversky, A., Sattath, S., \& Slovic, P. (1988). Contingent weighting in judgment and choice. Psychological Review, 95, 371-384.

Tversky, A., Slovic, P., \& Kahneman, D. (1990). The causes of preference reversal. American Economic Review, 80, 204-217.

Weber, E., Anderson, C., \& Birnbaum, M. (in press). A theory of perceived risk and attractiveness. Organizational Behavior and Human Decision Processes.

Zakay, D. (1984). The relationship between preference strength and relative frequency of choice. Applied Psychological Measurement, $8,207-211$.

Received December 10, 1990

Revision received October 4, 1991

Accepted June 21, 1991 